\section{Human Heredity}

Barbujani, G. 119, 133

Buhler, S. 162

Claas, F. 178

Comas, D. 194

Currat, M. 142

Deguilloux, M.F. 121

Fellay, J. 187
Gerbault, P. 154

Kayser, M. 194

Lao, O. 194

Marigorta, U.M. 194

McLaren, P.J. 187

Mendisco, F. 121

Mendizabal, I. 194
Nunes, J.M. 162

Sanchez-Mazas, A. 119, 162

Silva, N.M. 142

Telenti, A. 187

Tiercy, J.-M. 178

\title{
Subject Index Vol. 76, No. 3-4, 2013
}

Admixture 133

Allele surfing 154

Alloreactivity 178

Ancient DNA 121, 133, 142, 154

Caucasian 162

Computer simulation 142

Demic diffusion 133

Demographic history 162

Disease risk 194

Epitopes 178

Europe 142

European 162

- populations 121

EUROSTAM 162

Evolutionary genomics 187

Exome sequencing 187
Founder effect 133

- population 194

Genetic continuity 121

- diversity 133, 162

Genome-wide association studies 187

Haplotype frequency 178

Hematopoietic stem cell transplantation 178

HLA 162

- haplotypes 162

- -NET 162

- polymorphism 178

Homozygosity 194

Host-pathogen interactions 187

Human populations 162

Immunogenetics 187

Infectious diseases 187
Kidney transplantation 178

Lactase persistence 154

Linkage disequilibrium 162

Mitochondrial DNA 121

Multi-allelic loci 162

Natural selection 162

Neolithic period 154

- transition 121

Phenotypic variation 162

Population data 162

- genetics 133, 142, 162

- history 194

Positive selection 154

Prehistory 142

Romani 194 